\title{
Reproductive Phenology and Size Structure Characteristics of Hypseleotris agilis (Herre, 1927) in Lake Mainit, Philippines
}

\author{
Joycelyn C. Jumawan ${ }^{1, a^{*}}$, Paula Marie P. Hidalgo ${ }^{1, b}$, Romell A. Seronay ${ }^{2, c}$ \\ ${ }^{1}$ Department of Biology, College of Arts and Sciences, Caraga State University, Butuan City, \\ Philippines
}
${ }^{2}$ Department of Environmental Sciences, College of Forestry And Environmental Science, Caraga State University, Butuan City, Philippines

ajoycejumawan1981@gmail.com, b hpaulamarie@gmail.com, c romell.seronay@gmail.com

\section{Keywords: Kalinawan River, Lake Mainit, Fisheries}

\begin{abstract}
Hypseleotris agilis locally known as Bugwan, is a native species of commercial value in Lake Mainit, Philippines. A total of 1,584 H. agilis from Lake Mainit near the mouth of Kalinawan and Puyo River were caught from May 2018 to February 2019 to determine the length-weight relationship (LWR), condition factor (K), gonadosomatic index (GSI) and hepatosomatic index (HSI) of this species. Positive allometric growth was observed for both sexes $(b>3)$. Sex ratio indicated the dominance of males over females as much as $58.7 \%$. The number of ripe males and gravid females was observed throughout the months of the collection, which indicates the ability of the fish species to spawn continuously throughout the year. The determination of GSI in both sexes showed higher values during November (males) and December (females). However, HSI values were relatively low during the spawning season, which would indicate the usage of energy for gonadal maturation. The $\mathrm{K}$ factor showed high values during the peak spawning months, directly proportional to GSI values. This study provides baseline information on reproductive parameters and size structure for the management and conservation of this important fishery resource in Lake Mainit.
\end{abstract}

\section{Introduction}

An understanding of the reproductive biology of a species is vital in providing sound scientific advice for fisheries management [1,2]. Parameters such as the gonado-somatic indices and lengthweight relationships in a species are essential tools for the analysis of the growth patterns by the allometric coefficients, and in obtaining body conditions of the fish specimens $[3,4,5]$. These parameters also provide insights into the reproductive strategy of the fish [6].

Lake Mainit is an essential body of water geographically situated between the provinces of Agusan del Norte and Surigao del Norte, Philippines. It is considered as the country's fourth-largest $(17,060 \mathrm{ha})$ and deepest $(219.35 \mathrm{~m})$ lake [7,8] This lake is known to have 28 river tributaries that are drained into Kalinawan River.

The eleotrid Hypseleotris agilis locally known as "bugwan" is an endemic and commercially important fish found in Lake Mainit [7]. The species is omnivorous and thrives in the littoral zone of the lake. Their abundance in the lake has been threatened by overfishing, and their recruitment may have been reduced by the continued use of fine-meshed nets and other illegal fishing gears [9]. De Guzman et al. [10] reported that $H$. agilis from Lake Mainit is generally smaller in sizes compared to their documented sizes in the 1990s. In Lake Lanao, this species was noted to be the cause of the decline of the endemic cyprinid population due to competition and predation [11]. Changes in the population dynamics of $H$. agilis is of interest to fishery resource managers, and detailed information of their biology is essential for monitoring and development measures to sustain this species in Lake Mainit. 


\section{Materials and Methods}

\section{Description of the study area}

Lake Mainit falls within the jurisdiction of the municipality of Mainit, Alegria, Kitcharao, and Jabonga. Hypseleotris agilis were collected in Lake Mainit near the mouth of Kalinawan River $\left(9^{\circ}\right.$ $\left.20^{\prime} 24^{\prime \prime} \mathrm{N}, 125^{\circ} 31^{\prime} 12^{\prime \prime} \mathrm{E}\right)$ and Puyo River $\left(9^{\circ} 18^{\prime} 18^{\prime \prime} \mathrm{N}\right.$ and $\left.125^{\circ} 31^{\prime} 41^{\prime \prime} \mathrm{E}\right)$ (Figure 1) both located in the Municipality Jabonga. Lake Mainit drains into Kalinawan River, which passes through the municipalities of Jabonga, Santiago, and Tubay before it empties in Butuan Bay.

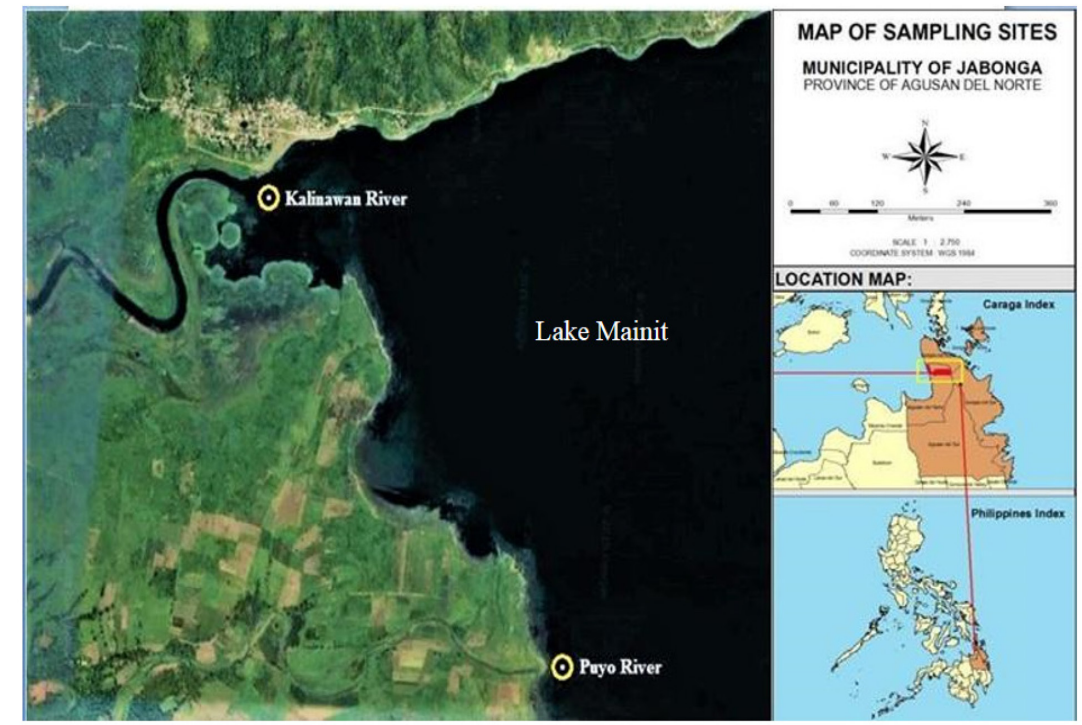

Figure 1. Map of Lake Mainit where Hypseleotris agilis were collected

\section{Collection and processing of Hypseleotris agilis}

The fish samples were randomly caught within the river mouths of Kalinawan River and Puyo River every month from May 2018 to February 2019, with a minimum of 30 individuals per sex/month. A bottom set long line, 10 meters long, was established in the river mouths with approximately 300 hooks attached to it. Fishes were later placed in an ice bucket and brought to the laboratory for the measurements of total body length (TL; $\mathrm{cm}$ ) using a caliper and body weight $(\mathrm{g})$ using a top-loading balance.

The length-weight relationship (LWR) was expressed by the equation $\mathrm{W}=a \mathrm{~L}^{\mathrm{b}}$, where $\mathrm{W}$ is the total body weight, ' $a$ ' as the regression intercept, ' $L$ ' as the standard length, and ' $b$ ' as the regression coefficient [4]. The parameters $a, b$, and $\mathrm{r}^{2}$ (coefficient of determination) were estimated by the leastsquares regression analysis of the logarithm-transformed LWR expression Log W $=b \log \mathrm{L}+\log a$ with "W" as the dependent variable. The ' $b$ ' is an exponent with a value between 2.5 and 3.5 to describe normal growth dimensions of relative well-being [6]. The Fulton's condition factor (K) was computed for each specimen using the equation: $\mathrm{K}=\left(\mathrm{BW}_{\mathrm{SL}}{ }^{3}\right) \times 100$ [12].

Fishes were dissected to expose the gonads and liver which were later weighed for gonadosomatic (GSI) and hepatosomatic indices (HSI) as GSI= [(gonad weight)/(bodyweight) $] \times 100$ and HSI= [(liver weight)/(bodyweight)] x 100 [3] respectively. Description of macroscopic gonad maturation of Hypseleotris agilis: Stage 1 (Immature); Stage II (Maturing Virgin or Resting); Stage III (Developing); Stage IV (Gravid/Ripe) and Stage V (Spent) was adapted from De Guzman et al. [8].

\section{Statistical Analysis}

All data were recorded in Microsoft Excel. IBM SPSS was used to analyze regression data between different frequencies (length vs. weight). A comparison of regression parameter $b$ between sexes was made using the T-test, and comparison between months was made using Analysis of Covariance (ANCOVA). 


\section{Results}

A total of 1,584 individuals of the fish species were caught from May 2018 to February 2019, which comprises of $930(58.7 \%)$ males and $654(41.2 \%)$ females. The sex ratio was 1.422 male: 1 female (Table 1), contrary to the previous reports of Calicia and Lopez [13] where female H. agilis were more abundant over males as much as 16\% and De Guzman et al. [8] where monthly sex ratios of mature individuals show more females (M: F 1:1.4) than males in Lake Mainit.

Table 1. Length-weight relationships (LWRs) of H. agilis from Lake Mainit, Philippines

\begin{tabular}{|c|c|c|c|c|c|c|}
\hline SEX & $\mathbf{n}$ & $\begin{array}{c}\mathbf{b} \\
(95 \% \mathrm{CI})\end{array}$ & $\begin{array}{c}\mathbf{a} \\
(95 \% \mathrm{CI})\end{array}$ & $\mathbf{r}^{2}$ & $\begin{array}{c}\text { TOTAL } \\
\text { LENGTH (cm) }\end{array}$ & BODY WEIGHT (g) \\
\hline Female & 654 & 3.070 & -1.947 & 0.870 & $10.9(7.2-18.9)$ & $46.01(5.28-86.74)$ \\
\hline Male & 930 & 3.013 & -1.441 & 0.821 & $10.39(7-18.6)$ & $46.01(4.42-87.61)$ \\
\hline Pooled & 1584 & 3.091 & -1.625 & 0.857 & $10.6(7-18.9)$ & $46.01(4.42-87.61)$ \\
\hline
\end{tabular}

The maximum TL of $H$. agilis for females and males were 18.9 and $18.7 \mathrm{~cm}$, respectively. These sizes were slightly larger than from the study of De Guzman et al. [10] at $18 \mathrm{~cm}$ and Calicia and Lopez [13] at $18.5 \mathrm{~cm}$. Females were observed to be slightly larger than males (Table 1. Both the males and females showed a positive allometric growth pattern with a regression slope $(b)$ value of 3.013 and 3.070, respectively (Table 1; Figure 2). The $b$ value for the combined sexes also indicates positive allometric growth $(b=3.091)$, which suggests that the weight of $H$. agilis is more inclined to grow faster than that of the length, similar to the findings of De Guzman et al. [10]. The $b$ values obtained in this study fall within 2.5-3.5 and are close to 3, the typical ranges for $b$ in fishes [4]. Since an ideal fish maintains equality in its dimensions, an isometric value of $b=3$ is observed in many fish species [6]. A $b$ value of less than three would show slenderness in the fish, as it becomes thinner with the increase in its length.

Of the total number of fish species caught from May 2018 to February 2019, the size class range $6-10 \mathrm{~cm}$ dominated the overall population with $67.55 \%$ (Figure 3). Ismail [14] reported that $H$. agilis in Lake Lanao is capable of growing until $18 \mathrm{~cm}$. In the current study, very few individuals, mostly females, reached this maximum TL, and BW, most likely as females, in general, tend to grow larger than males to accommodate the female gonads that contain the eggs [3]. Local fisherfolks confirm that larger male and female $H$. agilis (approximately $13-18 \mathrm{~cm}$ TL) are more inclined to stay in the deep, especially those that are of ripe and gravid stages (pers.comm.). The majority of H. agilis caught in the current study belong to the $6-10 \mathrm{~cm}$ TL size class range, especially the males (Figure 3). In December, no fish individuals in the $6-10 \mathrm{~cm}$ size class range were recorded, the majority of the fish caught in December were gravid males and females.

Studies have indicated differences in the body shape of the male and female $H$. agilis. In Lake Lanao, male $H$. agilis have bigger heads and a more elongated dorsal and anal fin bases as a possible result of sexual selection and ecological niche, respectively [15]. Ceniza et al. [16] also suggest sexual dimorphism in the species in Lake Mainit, where the mouth of males is bigger with its premaxilla leveling the anterior edge of the eye. Further, females have a shorter interneural gap of dorsal fins while males have a broader caudal peduncle needed for efficient guarding of eggs during the spawning season. Libay et al. [17] indicate that difference in shapes between the sexes of H. agilis in Lake Mainit could be a result of adaptation and selection pressure. 


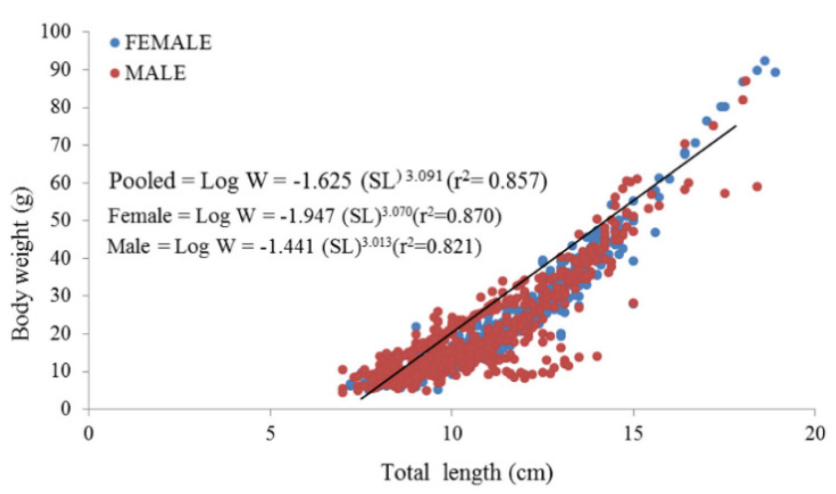

Figure 2. Length-weight relationships of male and female Hypseleotris agilis from lake Mainit, Philippines. No. of specimens: Males: 930; Females: 654

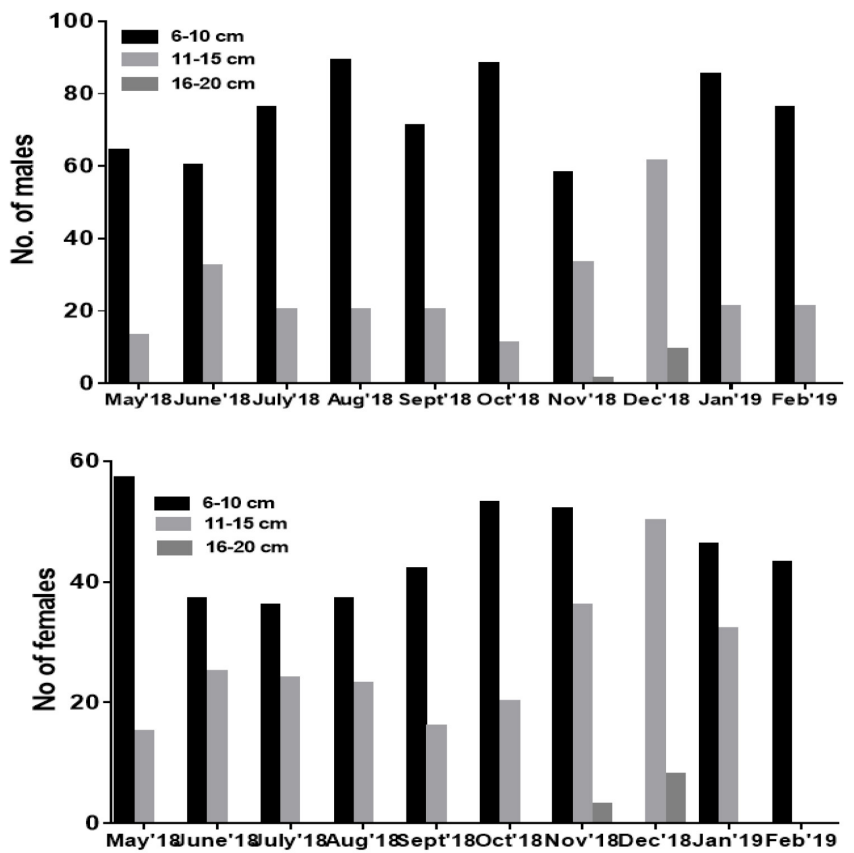

Figure 3. The ratio of male and female $H$. agilis in Lake Mainit in different size classes and across months of collection. No. of specimens: Males: 930; Females: 654

\section{Condition Factor of the Fish Species}

The condition factor $(\mathrm{K})$ is an essential biological parameter that describes the fitness state or the robustness of a fish. The highest $\mathrm{K}$ value $(1.83 \pm 0.002)$ for males was observed in November, and the minimum value $(1.25 \pm 0.0002)$ was noted in June. In females, the highest value $(1.89 \pm$ $0.001)$ was recorded in December, and the lowest $(1.28 \pm 0.0002)$ was observed in October (Figure 4). Analysis of Covariance showed no significant difference of $\mathrm{K}$ between sexes across size classes but showed significantly higher $\mathrm{K}(\mathrm{P}=0.05)$ of both sexes for December. Differences in $\mathrm{K}$ could be due to fatness, the suitability of the environment, or stage of gonad development $[4,6]$.

Reproductive Maturity Stages and Gonadosomatic Index

The gonad maturity characterization described that reproductive stages I and II were still in the immature phase while III, IV, and V were already considered developed/matured [8]. Monthly variations in the gonad maturity of $H$. agilis were observed during the sampling period. Individuals with immature gonad stages were sorted and were shown to illustrate their consistent presence throughout the sampling period (Figure 5). Numerous developing, gravid, and mature (Stage III and IV) males and females were also observed across the sampling period, which indicates the ability of the fish species to spawn continuously throughout the year. However, observations of more 
individuals in stage IV, which peaked in November, indicate peak reproduction on this month (Figure 4). The minimum TL for males with a developed stage (III) was $10.3 \mathrm{~cm}$ and $10.9 \mathrm{~cm}$ for females. For the gravid stage (IV), the minimum TL for males was observed at $15.3 \mathrm{~cm}$ and $14.3 \mathrm{~cm}$ for females. Males and females with the spent stage (V) were at $18.6 \mathrm{~cm}$ and $18.9 \mathrm{~cm}$ maximum TL respectively. Ismail [14] noted that the minimum length of $H$. agilis with reproductively mature gonads from Lake Lanao was at $8.7 \mathrm{~cm}$.

Female $H$ agilis with size ranges $11-18.9 \mathrm{~cm}$ TL registered GSI $>1.0$ across the study period except for June and October. Female GSI peaked in December. The GSI of male $H$ agilis, however, was shown to increase starting from November to February (Figure 6). These results were consistent with the macroscopic evaluation of gonad maturity (Figure 5) as well as with the previous reports that a large number of gravid $H$. agilis were recorded between November to January, with its peak occurring on December [8].

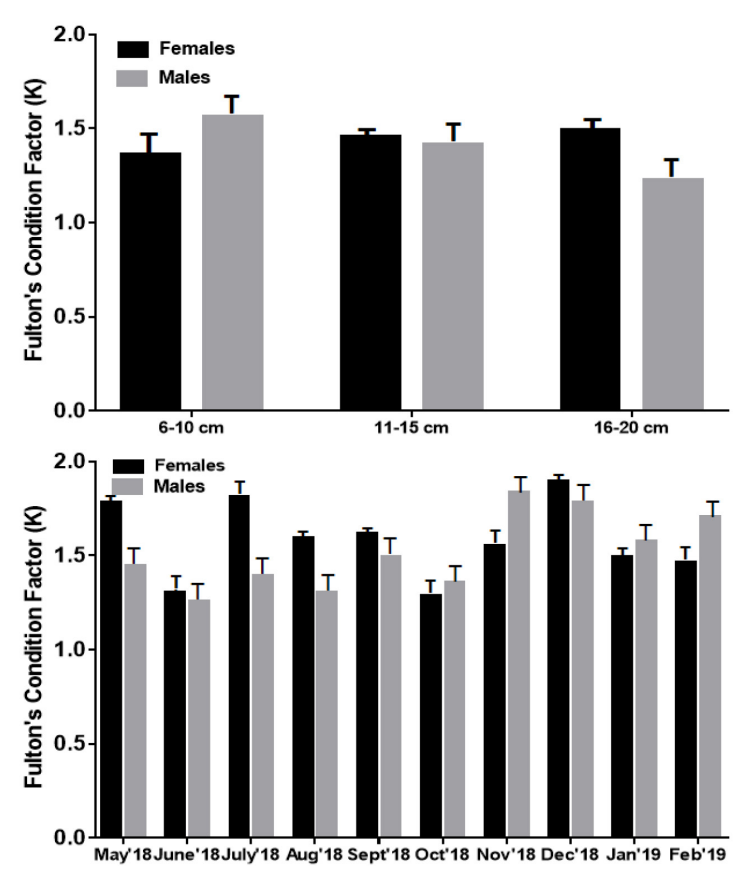

Figure 4. Condition factor $(\mathrm{K})$ of Hypseleotris agilis in Lake Mainit between size classes (above) and months of the collection (below). No. of specimens: Males: 930; Females: 654. Error bars represent standard error of the means

\section{Hepatosomatic Index}

The hepatosomatic index is often used to describe the energy reserves of an organism and its metabolic activities in response to water quality [6]. The maximum mean HSI was observed in October for females (1.35) and June for males (1.12). In contrast, the minimum mean HSI was noted in September for females (0.56) and November for males (0.15) (Figure 6). The low hepatosomatic index during the spawning season is usually exhibited by many fish species indicating that liver growth is limited because of the development of gonads [18]. The current data show that when the HSI values were at its lowest, the GSI values were at its peak. In female $H$. agilis, for example, December had the highest mean GSI but also had the lowest HSI. Females had the lowest GSI in October, but HSI was recorded highest on this month. During the spawning season, HSI values tend to decrease because energy reserves from the liver are consumed for the maturation of gonads [19]. 

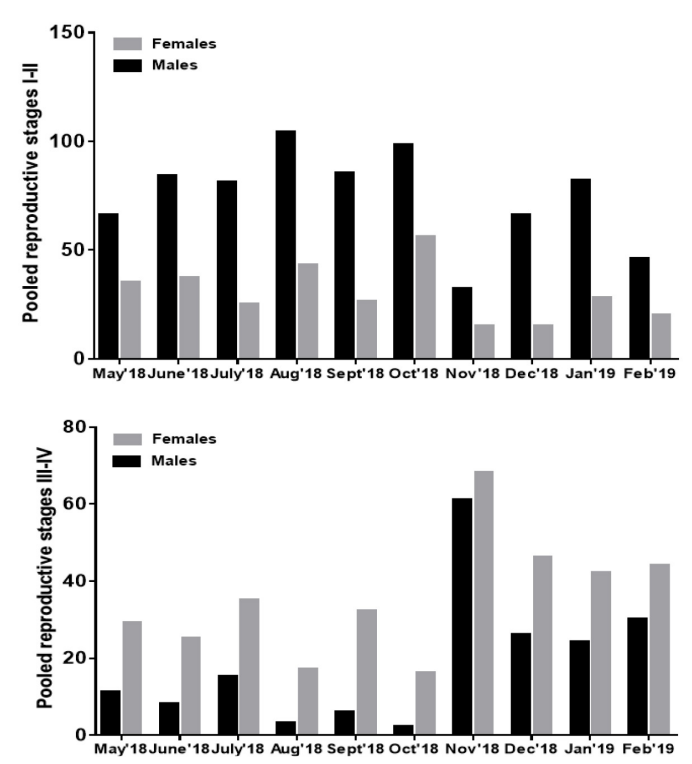

Figure 5. Pooled reproductive stages of Hypseleotris agilis during months of the collection in Lake Mainit Above: Immature stages I-II (N: Males=744; Females=300). Below: Mature stages III-IV (N: Males=180; Females $=344$ )
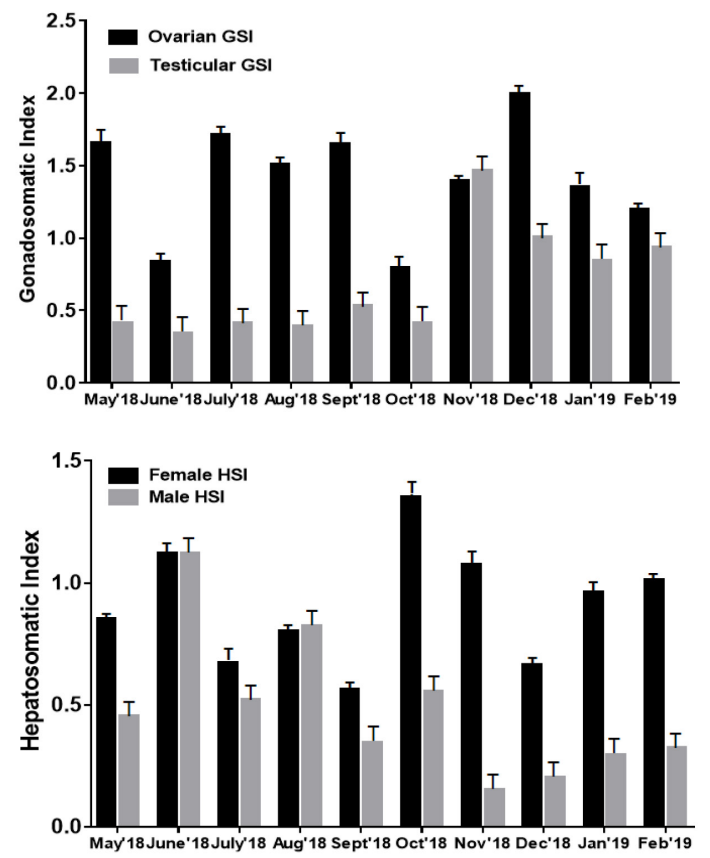

Figure 6. Gonadosomatic index (GSI) and Hepatososomatic index (HSI) of mature Hypseleotris agilis in Lake Mainit, Philippines. No. of specimens: Males: 930; Females: 654. Error bars represent standard error of the means

\section{Conclusion}

This study provides updated information on the length-weight relationships, condition factor, gonadosomatic, and hepatosomatic index of $H$. agilis in Lake Mainit. As an essential fishery resource in the lake, the current update on $H$. agilis may be used for proper fishery management and conservation of this species. Both surveys of gonad maturity staging and GSI show that the fish spawns throughout the sampling period with peak GSI in November for males and December for females, consistent with the previous reports. Reproductive phenology using fecundity estimates and fisheries monitoring through Catch per Unit Effort (CPUE) is recommended as additional monitoring strategies. 


\section{Conflict of Interest}

The authors have no conflict of interest.

\section{Acknowledgment}

The authors would like to thank the local government of the municipality of Jabonga for allowing the collection of samples in the area.

\section{References}

[1] M.J. Morgan. Integrating reproductive biology into scientific advice for fisheries management. Journal of Northwest Atlantic Fishery Science. 41 (2008), 37-51.

[2] H. Murua, et al., Procedures to estimate fecundity of marine fish species from field samples in relation to reproductive strategy. Journal of Northwest Atlantic Fishery Science. 33 (2003) 3354.

[3] J.C. Jumawan, A.A. Herrera, Ovary morphology and reproductive features of the female suckermouth sailfin catfish, Pterygoplichthys disjunctivus (Weber 1991) from Marikina River, Philippines. Asian Fisheries Science. 27(2014) 75-89.

[4] R. Froese, Cube law, condition factor and weight-length relationships: history, meta-analysis and recommendations. Journal Applied Ichthyology 22 (2006) 241-253.

[5] J.C. Jumawan, R.A. Seronay, Length-weight relationship of fishes in eight floodplain lakes of Agusan Marsh, Philippines. Philippine Journal of Science. 146 (2017) 95-99.

[6] T. Bolger, P.L. Connolly, The selection of suitable indices for the measurement and analysis of fish condition. Journal of Fish Biology. 34 (1989) 171-182.

[7] M. Tumanda Jr, et al., Limnological and water quality assessment of Lake Mainit. Mindanao State University, Naawan (2003) 300p.

[8] A.B. De Guzman et al., Sustainable Fisheries Management Program for Lake Mainit: Phase I: Rapid Resource Assessment. Inception Report. Prepared by MSU at Naawan for the PCAMRD-DOST (2008) 75 p.

[9] L.R. Cagata et al., Variability between and among colormorphs of the goby fish, Hypseleotris agilis Herre (Perciformes: Eleotridae). Journal of Nature Studies. 9 (2010):149-155.

[10] A.B. De Guzman et al., Sustainable Fisheries Management Program for Lake Mainit: Phase II: Comprehensive Resource Assessment. Final Report. MSU at Naawan Foundation for Science and Technology Development-Northern Mindanao Community Initiatives in Resource Management (IFAD-NMCIREMP), Department of Agrarian Reform 13, Lake Mainit Development Alliance (LMDA) and PCAMRD-DOST (2009) 73p.

[11] P.T. Escudero, M.A. Demoral, Preliminary studies on the Biology and Fishery of Hypseleotris agilis Herre. Journal of Fisheries and Aquaculture. 4 (1983) 3-89.

[12] D. Pauly, Fish population dynamics in tropical waters: a manual for use with programmable calculators. ICLARM Studies and Reviews 8 (1984) 325p.

[13] A.M. Calicia Jr, N.A. Loez, The biology and fishery of Indigenous Gobies of Lake Mainit, Philippines. In: De Silva S.S., (ed) Reservoir and culture-based fisheries: Biology and Management (1998) $384 \mathrm{p}$.

[14] G.B. Ismail, The status and life history traits of endemic, native and introduced species in Lake Lanao, Philippines. MS Thesis. Oregon State University (2011) 256p. 
[15] S.S. Nacua, et al., Sexual Dimorphism in Body Shape of Hypseleotris agilis (Herre, 1927) from Lake Lanao, Philippines. ISCA Journal of Biological Sciences 1 (2012) 25-31.

[16] K.M. Unito-Ceniza et al., Describing the body shape variation between sexes of an endemic eleotrid fish Hypseleotris agilis (Herre 1927), from Lake Mainit, using Landmark-Based Geometric Morphometrics. International Journal of Biological, Ecological and Environmental Sciences. 1(2012) 201-204.

[17] C.P. Libay et al., Geometric morphometric analysis in determining phenotypic variability of Bugwan,(Hypseleotris agilis, Herre) in Lake Mainit, Philippines. International Journal of Biosciences. 14 (2019) 61-70.

[18] B. Peña-Mendoza et al., Reproductive biology of Oreochromis niloticus (Perciformes: Cichlidae) at Emiliano Zapata dam, Morelos, Mexico. Revista de Biología Tropical. 53(2005): 515-522.

[19] M. Huber, D.A.,Bengtson, Effects of photoperiod and temperature on the regulation of the onset of maturation in the estuarine fish Menidia beryllina (Cope) (Atherinidae). Journal of Experimental Marine Biology and Ecology. 240 (1999): 285-302. 